\title{
The role of differential and integral experiments to meet requirements for improved nuclear data
}

\author{
M. Salvatores ${ }^{1,2}$, G. Aliberti $^{1}$, and G. Palmiotti ${ }^{1}$ \\ 1 Argonne National Laboratory, Argonne, IL 60439, USA \\ 2 CEA Cadarache, 13108 Saint-Paul-lez-Durance, France
}

\section{Introduction}

A formal procedure can be used to assess the nuclear data uncertainty reductions needed in order to meet target accuracies on crucial design integral parameters, if target uncertainties have been agreed on these design parameters.

In the present paper, we used the covariance information and the resulting uncertainties on advanced reactor systems, both described in ref. [1] as part of the activity of the OECDNEA WPEC Subgroup 26, to investigate data target accuracies and possible approaches to meet them.

\section{Data target accuracies}

Within Subgroup 26, a preliminary list of design target accuracies for fast reactor systems (at first, independently of the coolant or the fuel type) has been agreed upon, see table 1 , for high burn-up PWRs, see table 2, and for (V)HTRs, see table 3. These target accuracies reflect the perceived status of the art, even if they are not the result of a systematic analysis, which should necessarily involve industrial partners. Moreover, it has to be kept in mind that no well defined "images" for any of the Gen-IV exist at present. This means that the target accuracies shown in particular in table 1 reflect the current thinking of systems with innovative fuels and core configurations described in ref. [1], i.e. the Na-cooled systems (burners with different fuel types as the SFR and ABTR, or self-sustaining as the EFR), gas-cooled GFR and lead-cooled LFR. The case of the (V)HTR is somewhat different, since the target accuracies shown in table 3 were suggested by a major industry (AREVA).

Table 1. Fast reactor target accuracies $(1 \sigma)$.

\begin{tabular}{|l|l|}
\hline Multiplication factor (BOL) & $300 \mathrm{pcm}$ \\
\hline Peak power (BOL) & $2 \%$ \\
\hline Burn-up reactivity swing & $300 \mathrm{pcm}$ \\
\hline Reactivity coefficients (coolant void and Doppler - BOL) & $7 \%$ \\
\hline Major nuclide density at end of irradiation cycle & $2 \%$ \\
\hline Other nuclide density at end of irradiation cycle & $10 \%$ \\
\hline
\end{tabular}

Table 2. PWR target accuracies $(1 \sigma)$.

\begin{tabular}{|c|c|c|c|}
\hline $\mathrm{k}_{\mathrm{eff}}$ & $\begin{array}{c}\text { Temperature reactivity } \\
\text { coefficient }\end{array}$ & Burn-up $\Delta \rho$ & Transmutation \\
\hline $0.5 \%$ & $10 \%$ & $500 \mathrm{pcm}$ & $5 \%$ \\
\hline
\end{tabular}

Table 3. Target accuracy $(1 \sigma)$ for $\mathrm{UO}_{2}$ - and $\mathrm{PuO}_{2}$-fuelled HTR's (Source: AREVA-NP, reproduced with permission for WPEC SG26).

\begin{tabular}{|c|c|}
\hline Criticality & $\begin{array}{c}300 \mathrm{pcm} \text { (operation); } 500 \mathrm{pcm} \\
\text { (safety) }\end{array}$ \\
\hline Local power (in fuel compact) & $\begin{array}{c}6 \% \text { (2\% in pin-wise fission rate } \\
\text { of fresh fuel; } 4 \% \text { in main fissile } \\
\text { isotope conc. of irradiated fuel) }\end{array}$ \\
\hline Burn-up (cycle length) & $1 \%(. \Rightarrow \sim 500 \mathrm{MWd} / \mathrm{t})$ \\
\hline Doppler coefficient & $20 \%$ \\
\hline Moderator temperature coeff. & $1 \mathrm{pcm} /{ }^{\circ} \mathrm{C}$ \\
\hline Nuclide inventories at EOL & $4 \%$ \\
Main fissile isotopes & $5 \%$ \\
Fertile isotopes & $20 \%$ \\
MAs and FPs & \\
\hline
\end{tabular}

Once the design target accuracies have been defined, the formal procedure to obtain the unknown uncertainty nuclear data requirements $d_{i}$ implies solving the following minimization problem with constraints (see, e.g., ref. [2]):

$$
\begin{gathered}
\sum_{i} \lambda_{i} / d_{i}^{2}=\min \quad i=1 \ldots I . \\
\sum_{i} S_{n i}^{2} d_{i}^{2} \leq\left(Q_{n}^{T}\right)^{2} n=1 \ldots N
\end{gathered}
$$

(where $I$ is the number of nuclear data, $N$ is the number of integral parameters, $S_{n i}$ are the sensitivity coefficients for the integral parameter $Q_{n}$, and $Q_{n}^{T}$ are the target accuracies on the $N$ integral parameters), the $\lambda_{i}$ which are "cost" parameters related to each $\sigma_{i}$, can be used to give a relative figure of merit of the difficulty of improving that parameter (e.g., with a differential experiment).

As already done in previous work [2], we used at first a constant value of one for all $\lambda$. The results given in table 4 are relevant to the ABTR. 
Table 4. ABTR: Uncertainty reduction requirements needed to meet integral parameter target accuracies.

\begin{tabular}{|c|c|c|c|c|c|}
\hline \multirow{3}{*}{ Isotope } & \multirow{3}{*}{$\begin{array}{l}\text { Cross- } \\
\text { Section }\end{array}$} & \multirow{3}{*}{ Energy Range } & \multicolumn{3}{|c|}{ Uncertainty (\%) } \\
\hline & & & \multirow[b]{2}{*}{ Initial } & \multicolumn{2}{|c|}{ Required } \\
\hline & & & & $\lambda=1$ & $\lambda \neq \mathbf{1}^{(a)}$ \\
\hline \multirow{3}{*}{ U238 } & \multirow{3}{*}{$\sigma_{\text {inel }}$} & $6.07-2.23 \mathrm{MeV}$ & 19.8 & 3.3 & 5.8 \\
\hline & & $2.23-1.35 \mathrm{MeV}$ & 20.6 & 3.6 & 6.3 \\
\hline & & $1.35-0.498 \mathrm{MeV}$ & 11.6 & 6.5 & 11.4 \\
\hline U238 & $\sigma_{\text {capt }}$ & $24.8-9.12 \mathrm{keV}$ & 9.4 & 2.9 & 1.6 \\
\hline \multirow{4}{*}{ Pu239 } & \multirow{4}{*}{$\sigma_{\text {capt }}$} & $498-183 \mathrm{keV}$ & 11.6 & 5.7 & 3.2 \\
\hline & & $183-67.4 \mathrm{keV}$ & 9.0 & 5.0 & 2.8 \\
\hline & & $67.4-24.8 \mathrm{keV}$ & 10.1 & 5.8 & 3.2 \\
\hline & & $9.12-2.04 \mathrm{keV}$ & 15.5 & 7.4 & 4.1 \\
\hline Pu241 & $\sigma_{\text {fiss }}$ & $183-67.4 \mathrm{keV}$ & 19.9 & 8.8 & 7.0 \\
\hline \multirow{2}{*}{ Fe56 } & \multirow{2}{*}{$\sigma_{\text {inel }}$} & $2.23-1.35 \mathrm{MeV}$ & 25.4 & 5.6 & 9.9 \\
\hline & & $1.35-0.498 \mathrm{MeV}$ & 16.1 & 7.5 & 13.1 \\
\hline $\mathrm{Na23}$ & $\sigma_{\text {inel }}$ & $1.35-0.498 \mathrm{MeV}$ & 28.0 & 10.1 & 17.7 \\
\hline
\end{tabular}

(a) $\quad \lambda_{\text {inel }}=10 ; \lambda_{\text {el }}=1 ; \lambda_{\text {capt }, \text { fiss }, v}(\mathrm{U} 235, \mathrm{U} 238, \mathrm{Pu} 239)=1 ; \lambda_{\text {capt,fiss }, v}$ $($ other fissiles $)=2 ; \lambda_{\text {capt }}($ structural $)=1$.

Table 5. Summary target accuracies for fast reactors.

\begin{tabular}{|c|c|c|c|c|}
\hline & & Energy Range & $\begin{array}{l}\text { Current } \\
\text { Accuracy } \\
(\%)\end{array}$ & \begin{tabular}{|l} 
Target \\
Accuracy $(\%)$
\end{tabular} \\
\hline U238 & $\begin{array}{l}\sigma_{\text {inel }} \\
\sigma_{\text {capt }}\end{array} \mid$ & $\begin{array}{l}6.07 \div 0.498 \mathrm{MeV} \\
24.8 \div 2.04 \mathrm{keV}\end{array}$ & $\begin{array}{l}10 \div 20 \\
3 \div 9\end{array}$ & $\begin{array}{l}2 \div 3 \\
1.5 \div 2\end{array}$ \\
\hline Pu241 & $\sigma_{\text {fiss }}$ & $1.35 \mathrm{MeV} \div 454 \mathrm{eV}$ & $8 \div 20$ & $\begin{array}{c}2 \div 3 \text { (SFR,GFR } \\
\text { LFR) } \\
5 \div 8 \text { (ABTR,EFR) }\end{array}$ \\
\hline Pu239 & $\sigma_{\text {capt }}$ & $498 \div 2.04 \mathrm{keV}$ & $7 \div 15$ & $4 \div 7$ \\
\hline Pu240 & $\begin{array}{l}\sigma_{\text {fiss }} \\
v\end{array}$ & $\begin{array}{l}1.35 \div 0.498 \mathrm{MeV} \\
1.35 \div 0.498 \mathrm{MeV}\end{array}$ & $\begin{array}{l}6 \\
4\end{array}$ & $\begin{array}{l}1.5 \div 2 \\
1 \div 3\end{array}$ \\
\hline Pu242 & $\sigma_{\text {fiss }}$ & $2.23 \div 0.498 \mathrm{MeV}$ & $19 \div 21$ & $3 \div 5$ \\
\hline Pu238 & $\sigma_{\text {fiss }}$ & $1.35 \div 0.183 \mathrm{MeV}$ & 17 & $3 \div 5$ \\
\hline Am242m & $\sigma_{\text {fiss }}$ & $1.35 \mathrm{MeV} \div 67.4 \mathrm{keV}$ & 17 & $3 \div 4$ \\
\hline Am241 & $\sigma_{\text {fiss }}$ & $6.07 \div 2.23 \mathrm{MeV}$ & 12 & 3 \\
\hline Cm244 & $\sigma_{\text {fiss }}$ & $1.35 \div 0.498 \mathrm{MeV}$ & 50 & 5 \\
\hline Cm245 & $\sigma_{\text {fiss }}$ & $183 \div 67.4 \mathrm{keV}$ & 47 & 7 \\
\hline textbfFe 56 & $\sigma_{\text {inel }}$ & $2.23 \div 0.498 \mathrm{MeV}$ & $16 \div 25$ & $3 \div 6$ \\
\hline $\mathrm{Na23}$ & $\sigma_{\text {inel }}$ & $1.35 \div 0.498 \mathrm{MeV}$ & 28 & $4 \div 10$ \\
\hline Pb206 & $\sigma_{\text {inel }}$ & $2.23 \div 1.35 \mathrm{MeV}$ & 14 & 3 \\
\hline Pb207 & $\sigma_{\text {inel }}$ & $1.35 \div 0.498 \mathrm{MeV}$ & 11 & 3 \\
\hline $\mathbf{S i 2 8}$ & $\begin{array}{l}\sigma_{\text {inel }} \\
\sigma_{\text {capt }}\end{array}$ & $\begin{array}{l}6.07 \div 1.35 \mathrm{MeV} \\
19.6 \div 6.07 \mathrm{MeV}\end{array}$ & $\begin{array}{l}14 \div 50 \\
53\end{array}$ & $\begin{array}{l}3 \div 6 \\
6 \\
\end{array}$ \\
\hline
\end{tabular}

To have a first indication of the impact of the choice of the $\lambda_{i}$ parameters, related to achievable experimental uncertainties for $\sigma_{\text {fiss }}, \sigma_{\text {capt }}, \sigma_{\text {inel }}$ measurements for actinide and structural materials, a different set of $\lambda$ values was used (as indicated in table 4), with the purpose to stress, as an example, the difficulty to improve $\sigma_{\text {inel }}$, with respect to $\sigma_{\text {fiss }}$. The results show that, if we relax the accuracy requirement on $\sigma_{\text {inel }}$, a higher accuracy on $\sigma_{\text {capt }}$ and $\sigma_{\text {fiss }}$ is required. In absence of a systematic experimental study, we used $\lambda=1$ to obtain a first comprehensive set of data accuracy requirements.

In order to quantify specific nuclear data target accuracies, we considered the design parameters for which design target accuracies were available (see tables 1, 2 and 3). The
Table 6. SFR: Uncertainty reduction requirements needed to meet integral parameter target accuracies.

\begin{tabular}{|c|c|c|c|c|}
\hline \multirow{2}{*}{ Isotope } & \multirow{2}{*}{$\begin{array}{c}\text { Cross- } \\
\text { Section } \\
\end{array}$} & \multirow{2}{*}{ Energy Range } & \multicolumn{2}{|c|}{ Uncertainty (\%) } \\
\hline & & & Initial & Required $(\lambda=1)$ \\
\hline \multirow{5}{*}{ Pu241 } & \multirow{5}{*}{$\sigma_{\text {fiss }}$} & $1.35-0.498 \mathrm{MeV}$ & 16.6 & 3.4 \\
\hline & & $498-183 \mathrm{keV}$ & 13.5 & 2.6 \\
\hline & & $183-67.4 \mathrm{keV}$ & 19.9 & 2.6 \\
\hline & & $24.8-9.12 \mathrm{keV}$ & 11.3 & 3.5 \\
\hline & & $2.04-0.454 \mathrm{keV}$ & 12.7 & 4.4 \\
\hline \multirow{2}{*}{ Fe56 } & \multirow[b]{2}{*}{$\sigma_{\text {inel }}$} & $2.23-1.35 \mathrm{MeV}$ & 25.4 & 3.3 \\
\hline & & $1.35-0.498 \mathrm{MeV}$ & 16.1 & 3.2 \\
\hline $\mathrm{Na23}$ & $\sigma_{\text {inel }}$ & $1.35-0.498 \mathrm{MeV}$ & 28.0 & 4.0 \\
\hline Cm244 & $\sigma_{\text {fiss }}$ & $1.35-0.498 \mathrm{MeV}$ & 50.0 & 5.1 \\
\hline \multirow{6}{*}{ Am242m } & \multirow{6}{*}{$\sigma_{\text {fiss }}$} & $1.35-0.498 \mathrm{MeV}$ & 16.5 & 4.2 \\
\hline & & $498-183 \mathrm{keV}$ & 16.6 & 3.1 \\
\hline & & $183-67.4 \mathrm{keV}$ & 16.6 & 3.1 \\
\hline & & $67.4-24.8 \mathrm{keV}$ & 14.4 & 4.0 \\
\hline & & $24.8-9.12 \mathrm{keV}$ & 11.8 & 4.2 \\
\hline & & $2.04-0.454 \mathrm{keV}$ & 12.2 & 5.1 \\
\hline Pu240 & $\sigma_{\text {fiss }}$ & $1.35-0.498 \mathrm{MeV}$ & 5.8 & 1.8 \\
\hline Pu240 & $v$ & $1.35-0.498 \mathrm{MeV}$ & 3.7 & 1.5 \\
\hline \multirow{3}{*}{ Pu238 } & \multirow{3}{*}{$\sigma_{\text {fiss }}$} & $2.23-1.35 \mathrm{MeV}$ & 33.8 & 5.6 \\
\hline & & $1.35-0.498 \mathrm{MeV}$ & 17.1 & 3.3 \\
\hline & & $498-183 \mathrm{keV}$ & 17.1 & 3.6 \\
\hline Pu238 & $v$ & $1.35-0.498 \mathrm{MeV}$ & 7.0 & 2.7 \\
\hline \multirow{2}{*}{ Pu242 } & \multirow[b]{2}{*}{$\sigma_{\text {fiss }}$} & $2.23-1.35 \mathrm{MeV}$ & 21.4 & 4.9 \\
\hline & & $1.35-0.498 \mathrm{MeV}$ & 19.0 & 3.5 \\
\hline Cm245 & $\sigma_{\text {fiss }}$ & $183-67.4 \mathrm{keV}$ & 47.5 & 6.7 \\
\hline Pu242 & $\sigma_{\text {capt }}$ & $24.8-9.12 \mathrm{keV}$ & 38.6 & 8.4 \\
\hline U238 & $\sigma_{\text {capt }}$ & $24.8-9.12 \mathrm{keV}$ & 9.4 & 4.3 \\
\hline Fe56 & $\sigma_{\text {capt }}$ & $2.04-0.454 \mathrm{keV}$ & 11.2 & 5.3 \\
\hline
\end{tabular}

procedure indicated above was applied to all nuclear data whose uncertainty gave a contribution to the integral parameter uncertainty above a pre-defined threshold.

Table 5 shows a summary of the results obtained over the whole set of fast reactors. Values are given as uncertainty ranges within selected energy intervals and only the most significant values are shown.

Several significant features can be pointed out. As expected from the results of the uncertainty analysis (see ref. [2]), very tight requirements are shown for the $\sigma_{\text {inel }}$ of $\mathrm{U}-238$ (2-3\%), Fe-56 (3-6\%), Na-23 (4-10\%) and even for $\mathrm{Pb}$ isotopes. The required accuracies are probably beyond achievable limits with current techniques. As previously discussed, there are little margins to relax the requirements on $\sigma_{\text {inel }}$ if one does not want to produce comparably difficult requirements on some $\mathrm{Pu}$ isotope $\sigma_{\text {fiss }}$ and $\sigma_{\text {capt }}$.

In any case, the accuracy requirements for Pu isotopes are very tight (very often $<2-3 \%$ ).

As for $\sigma_{\text {capt }}$, the requirements for U-238 and Pu-239 aim to cut by more then a factor of 2 the current uncertainties.

In the case of minor actinides (MA), uncertainties improvements are in some cases are very significant. However, as we will see later on, this is the case when MA play an important role in the critical balance, and this is the case only for MA dedicated burner with a fuel heavily loaded with MA. For these very specific cases, the accuracy requirement for $\sigma_{\text {fiss }}$ of selected MA isotopes can go from 3 to $7 \%$. 
Table 7. EFR: Uncertainty reduction requirements needed to meet integral parameter target accuracies.

\begin{tabular}{|c|c|c|c|c|}
\hline \multirow{2}{*}{ Isotope } & \multirow{2}{*}{$\begin{array}{c}\text { Cross- } \\
\text { Section }\end{array}$} & \multirow{2}{*}{ Energy Range } & \multicolumn{2}{|c|}{ Uncertainty (\%) } \\
\hline & & & Initial & Required $(\lambda=1)$ \\
\hline \multirow{3}{*}{ U238 } & \multirow{3}{*}{$\sigma_{\text {inel }}$} & $6.07-2.23 \mathrm{MeV}$ & 19.8 & 3.7 \\
\hline & & $2.23-1.35 \mathrm{MeV}$ & 20.6 & 4.0 \\
\hline & & $1.35-0.498 \mathrm{MeV}$ & 11.6 & 5.0 \\
\hline $\mathbf{U} 238$ & $\sigma_{\text {capt }}$ & $24.8-9.12 \mathrm{keV}$ & 9.4 & 2.9 \\
\hline \multirow{2}{*}{016} & \multirow[b]{2}{*}{$\sigma_{\mathrm{abs}}$} & $19.6-6.07 \mathrm{MeV}$ & 100.0 & 14.2 \\
\hline & & $6.07-2.23 \mathrm{MeV}$ & 100.0 & 10.9 \\
\hline \multirow{2}{*}{ Fe56 } & \multirow{2}{*}{$\sigma_{\text {inel }}$} & $2.23-1.35 \mathrm{MeV}$ & 25.4 & 6.6 \\
\hline & & $1.35-0.498 \mathrm{MeV}$ & 16.1 & 8.4 \\
\hline \multirow{7}{*}{ Pu241 } & \multirow{7}{*}{$\sigma_{\text {fiss }}$} & $1.35-0.498 \mathrm{MeV}$ & 16.6 & 8.0 \\
\hline & & $498-183 \mathrm{keV}$ & 13.5 & 6.7 \\
\hline & & $183-67.4 \mathrm{keV}$ & 19.9 & 5.7 \\
\hline & & $67.4-24.8 \mathrm{keV}$ & 8.7 & 6.2 \\
\hline & & $24.8-9.12 \mathrm{keV}$ & 11.3 & 6.8 \\
\hline & & $9.12-2.04 \mathrm{keV}$ & 10.4 & 7.6 \\
\hline & & $2.04-0.454 \mathrm{keV}$ & 12.7 & 6.9 \\
\hline Pu240 & $\sigma_{\text {fiss }}$ & $1.35-0.498 \mathrm{MeV}$ & 5.8 & 3.5 \\
\hline \multirow{4}{*}{ Pu239 } & \multirow{4}{*}{$\sigma_{\text {capt }}$} & $183-67.4 \mathrm{keV}$ & 9.0 & 7.0 \\
\hline & & $67.4-24.8 \mathrm{keV}$ & 10.1 & 6.7 \\
\hline & & $24.8-9.12 \mathrm{keV}$ & 7.4 & 6.1 \\
\hline & & $9.12-2.04 \mathrm{keV}$ & 15.5 & 5.6 \\
\hline $\mathrm{Na23}$ & $\overline{\sigma_{\text {inel }}}$ & $1.35-0.498 \mathrm{MeV}$ & 28.0 & 7.9 \\
\hline \multirow{4}{*}{ Pu240 } & \multirow{4}{*}{$\sigma_{\text {capt }}$} & $498-183 \mathrm{keV}$ & 14.3 & 8.9 \\
\hline & & $183-67.4 \mathrm{keV}$ & 13.8 & 6.7 \\
\hline & & $67.4-24.8 \mathrm{keV}$ & 11.3 & 6.1 \\
\hline & & $24.8-9.12 \mathrm{keV}$ & 10.2 & 6.5 \\
\hline
\end{tabular}

Tables 6 to 9 give the details for each fast system (data for the ABTR were already summarized in table 4). Again, only the most significant data are shown.

In general, the priority is for U-238 (inelastic), $\mathrm{Pu}-239$ (capture), $\mathrm{Fe}-56$ and $\mathrm{Na}-23 \sigma_{\text {inel }}$ uncertainty reduction. The high content of $\mathrm{Pu}$ in the fuel and the relatively clean $\mathrm{Pu}$ vector are at the origin of this trend. The requirement for improved accuracy of the higher Pu isotopes, and in particular the fission of $\mathrm{Pu}-241$, becomes more stringent for the EFR, GFR and LFR cases. As indicated above, the requirements for improved MA data, are limited to the SFR case and only for selected isotopes and reactions. A few specific requirements are shown according to specificities of some cores, e.g. Si data requirements for the GFR and $\mathrm{Pb}$ data for the LFR.

Tables 10 and 11 give a summary of the main data requirements related to the thermal neutron systems, i.e., the VHTR (table 10) and the extended burn-up PWR (table 11). The present analysis indicates few significant requirements. In the case of the VHTR, it is required to improve Pu$241 \sigma_{\text {fiss }}$ below $\sim 400 \mathrm{eV}$. Pu-239 and Pu-241 very tight $\sigma_{\text {capt }}$ requirement below $\sim 0.5 \mathrm{eV}$ are also shown, together with $\mathrm{C}$ data improvements (both capture and inelastic) with respect to current uncertainty estimates. For the PWR with extended burn-up, we find the requirement to improve $\mathrm{Pu}-241$ and some O data.

The required accuracies are such that the design target accuracies are fulfilled in most cases. Table 12 gives a summary of the uncertainties of selected design parameters both with the original and with the required uncertainties, as obtained with
Table 8. GFR: Uncertainty reduction requirements needed to meet integral parameter target accuracies.

\begin{tabular}{|c|c|c|c|c|}
\hline \multirow{2}{*}{ Isotope } & \multirow{2}{*}{$\begin{array}{l}\text { Cross- } \\
\text { Section }\end{array}$} & \multirow{2}{*}{ Energy Range } & \multicolumn{2}{|c|}{ Uncertainty (\%) } \\
\hline & & & Initial & Required $(\lambda=1)$ \\
\hline \multirow{3}{*}{ U238 } & \multirow{3}{*}{$\sigma_{\text {inel }}$} & $6.07-2.23 \mathrm{MeV}$ & 19.8 & 1.6 \\
\hline & & $2.23-1.35 \mathrm{MeV}$ & 20.6 & 1.8 \\
\hline & & $1.35-0.498 \mathrm{MeV}$ & 11.6 & 2.4 \\
\hline \multirow[b]{2}{*}{ U238 } & \multirow[b]{2}{*}{$\sigma_{\text {capt }}$} & $24.8-9.12 \mathrm{keV}$ & 9.4 & 1.6 \\
\hline & & $9.12-2.04 \mathrm{keV}$ & 3.1 & 1.4 \\
\hline \multirow{7}{*}{ Pu241 } & \multirow{7}{*}{$\sigma_{\text {fiss }}$} & $1.35-0.498 \mathrm{MeV}$ & 16.6 & 3.5 \\
\hline & & $498-183 \mathrm{keV}$ & 13.5 & 3.1 \\
\hline & & $183-67.4 \mathrm{keV}$ & 19.9 & 2.5 \\
\hline & & $67.4-24.8 \mathrm{keV}$ & 8.7 & 2.5 \\
\hline & & $24.8-9.12 \mathrm{keV}$ & 11.3 & 2.6 \\
\hline & & $9.12-2.04 \mathrm{keV}$ & 10.4 & 2.2 \\
\hline & & $2.04-0.454 \mathrm{keV}$ & 12.7 & 2.8 \\
\hline Pu239 & $\sigma_{\text {capt }}$ & $9.12-2.04 \mathrm{keV}$ & 15.5 & 2.8 \\
\hline Si28 & $\sigma_{\text {capt }}$ & $19.6-6.07 \mathrm{MeV}$ & 52.9 & 5.6 \\
\hline \multirow[b]{2}{*}{ Si28 } & \multirow[b]{2}{*}{$\sigma_{\text {inel }}$} & $6.07-2.23 \mathrm{MeV}$ & 13.5 & 3.0 \\
\hline & & $2.23-1.35 \mathrm{MeV}$ & 50.0 & 5.8 \\
\hline $\mathrm{C}$ & $\sigma_{\mathrm{el}}$ & $1.35-0.498 \mathrm{MeV}$ & 5.0 & 1.7 \\
\hline Pu242 & $\sigma_{\text {fiss }}$ & $1.35-0.498 \mathrm{MeV}$ & 19.0 & 4.0 \\
\hline Pu240 & $\sigma_{\text {fiss }}$ & $1.35-0.498 \mathrm{MeV}$ & 5.8 & 2.2 \\
\hline Am241 & $\overline{\sigma_{\text {fiss }}}$ & $6.07-2.23 \mathrm{MeV}$ & 11.7 & 3.3 \\
\hline
\end{tabular}

Table 9. LFR: Uncertainty reduction requirements needed to meet integral parameter target accuracies.

\begin{tabular}{|c|c|c|c|c|}
\hline \multirow{2}{*}{ Isotope } & \multirow{2}{*}{$\begin{array}{c}\text { Cross- } \\
\text { Section }\end{array}$} & \multirow{2}{*}{ Energy Range } & \multicolumn{2}{|c|}{ Uncertainty (\%) } \\
\hline & & & Initial & Required $(\lambda=1)$ \\
\hline \multirow{3}{*}{ U238 } & \multirow{3}{*}{$\sigma_{\text {inel }}$} & $6.07-2.23 \mathrm{MeV}$ & 19.8 & 2.8 \\
\hline & & $2.23-1.35 \mathrm{MeV}$ & 20.6 & 2.3 \\
\hline & & $1.35-0.498 \mathrm{MeV}$ & 11.6 & 2.1 \\
\hline \multirow{3}{*}{ Pu241 } & \multirow{3}{*}{$\sigma_{\text {fiss }}$} & $1.35-0.498 \mathrm{MeV}$ & 16.6 & 3.7 \\
\hline & & $498-183 \mathrm{keV}$ & 13.5 & 2.6 \\
\hline & & \begin{tabular}{|l}
$183-67.4 \mathrm{keV}$ \\
\end{tabular} & 19.9 & 2.6 \\
\hline \multirow{3}{*}{ B10 } & \multirow{3}{*}{$\sigma_{\text {capt }}$} & $498-183 \mathrm{keV}$ & 15.0 & 2.4 \\
\hline & & $183-67.4 \mathrm{keV}$ & 10.0 & 2.3 \\
\hline & & $67.4-24.8 \mathrm{keV}$ & 10.0 & 2.7 \\
\hline U238 & $\sigma_{\text {capt }}$ & $24.8-9.12 \mathrm{keV}$ & 9.4 & 2.0 \\
\hline Pu240 & $\sigma_{\text {fiss }}$ & $1.35-0.498 \mathrm{MeV}$ & 5.8 & 1.6 \\
\hline Pu240 & $v$ & $1.35-0.498 \mathrm{MeV}$ & 3.7 & 1.3 \\
\hline \multirow{2}{*}{ Pu238 } & \multirow[b]{2}{*}{$\sigma_{\text {fiss }}$} & $1.35-0.498 \mathrm{MeV}$ & 17.1 & 3.3 \\
\hline & & $498-183 \mathrm{keV}$ & 17.1 & 3.4 \\
\hline \multirow{2}{*}{ Fe56 } & \multirow[b]{2}{*}{$\sigma_{\text {inel }}$} & $2.23-1.35 \mathrm{MeV}$ & 25.4 & 4.2 \\
\hline & & $1.35-0.498 \mathrm{MeV}$ & 16.1 & 3.6 \\
\hline Pb206 & $\sigma_{\text {inel }}$ & $2.23-1.35 \mathrm{MeV}$ & 14.2 & 3.3 \\
\hline Pb207 & $\sigma_{\text {inel }}$ & $1.35-0.498 \mathrm{MeV}$ & 11.3 & 3.0 \\
\hline Pu242 & $\overline{\sigma_{\text {fiss }}}$ & $1.35-0.498 \mathrm{MeV}$ & 19.0 & 3.9 \\
\hline Cm244 & $\sigma_{\text {fiss }}$ & $1.35-0.498 \mathrm{MeV}$ & 50.0 & 6.4 \\
\hline
\end{tabular}

the minimization procedure indicated above. In few cases only the residual uncertainties are slightly beyond the pre-defined target accuracies.

\section{Complementary use of experiments}

The very tight uncertainty requirements, discussed in the previous paragraph, suggest the complementary use of 
Table 10. VHTR: Uncertainty reduction requirements needed to meet integral parameter target accuracies.

\begin{tabular}{|c|c|c|c|c|}
\hline \multirow{2}{*}{ Isotope } & \multirow{2}{*}{$\begin{array}{l}\text { Cross- } \\
\text { Section }\end{array}$} & \multirow{2}{*}{ Energy Range } & \multicolumn{2}{|c|}{ Uncertainty (\%) } \\
\hline & & & Initial & Required $(\lambda=1)$ \\
\hline U238 & $\sigma_{\text {capt }}$ & $454-22.6 \mathrm{eV}$ & 1.7 & 1.2 \\
\hline $\mathrm{C}$ & $\sigma_{\text {scat }}$ & $19.6-6.07 \mathrm{MeV}$ & 30.0 & 7.1 \\
\hline \multirow[b]{2}{*}{ C } & \multirow[b]{2}{*}{$\sigma_{\mathrm{abs}}$} & $19.6-6.07 \mathrm{MeV}$ & 20.0 & 7.1 \\
\hline & & $4-0.54 \mathrm{eV}$ & 20.0 & 5.0 \\
\hline Pu239 & $\sigma_{\text {capt }}$ & $0.54 \mathrm{eV}-0.1 \mathrm{eV}$ & 1.4 & 0.9 \\
\hline \multirow{3}{*}{ Pu241 } & \multirow{3}{*}{$\sigma_{\text {fiss }}$} & $454-22.6 \mathrm{eV}$ & 19.4 & 6.4 \\
\hline & & $4-0.54 \mathrm{eV}$ & 26.8 & 9.4 \\
\hline & & $0.54 \mathrm{eV}-0.1 \mathrm{eV}$ & 2.9 & 1.5 \\
\hline Pu241 & $\sigma_{\text {capt }}$ & $0.54 \mathrm{eV}-0.1 \mathrm{eV}$ & 6.8 & 2.4 \\
\hline
\end{tabular}

Table 11. PWR: Uncertainty reduction requirements needed to meet integral parameter target accuracies.

\begin{tabular}{|c|c|c|c|c|}
\hline \multirow{2}{*}{ Isotope } & \multirow{2}{*}{$\begin{array}{l}\text { Cross- } \\
\text { Section }\end{array}$} & \multirow{2}{*}{ Energy Range } & \multicolumn{2}{|c|}{ Uncertainty (\%) } \\
\hline & & & Initial & Required $(\lambda=1)$ \\
\hline \multirow{2}{*}{$\mathbf{O}$} & \multirow[b]{2}{*}{$\sigma_{\mathrm{abs}}$} & $19.6-6.07 \mathrm{MeV}$ & 100.0 & 12.1 \\
\hline & & $6.07-2.23 \mathrm{MeV}$ & 100.0 & 9.9 \\
\hline \multirow{4}{*}{ Pu241 } & \multirow{4}{*}{$\sigma_{\text {fiss }}$} & $454-22.6 \mathrm{eV}$ & 19.4 & 4.7 \\
\hline & & $4-0.54 \mathrm{eV}$ & 26.8 & 7.7 \\
\hline & & $0.54 \mathrm{eV}-0.1 \mathrm{eV}$ & 2.9 & 1.7 \\
\hline & & $0.1 \mathrm{eV}$ - thermal & 3.3 & 1.9 \\
\hline Pu239 & $\sigma_{\text {capt }}$ & $0.54 \mathrm{eV}-0.1 \mathrm{eV}$ & 1.4 & 1.0 \\
\hline \multirow{2}{*}{ U238 } & \multirow[b]{2}{*}{$\sigma_{\text {capt }}$} & $24.8-9.12 \mathrm{keV}$ & 9.4 & 4.6 \\
\hline & & $454-22.6 \mathrm{eV}$ & 1.7 & 1.4 \\
\hline U238 & $\sigma_{\text {inel }}$ & $6.07-2.23 \mathrm{MeV}$ & 14.6 & 5.1 \\
\hline Pu241 & $\sigma_{\text {capt }}$ & $0.54 \mathrm{eV}-0.1 \mathrm{eV}$ & 6.8 & 3.0 \\
\hline Pu240 & $\sigma_{\text {capt }}$ & $0.1 \mathrm{eV}$ - thermal & 4.8 & 3.1 \\
\hline \multirow[b]{2}{*}{$\mathbf{O}$} & \multirow[b]{2}{*}{$\sigma_{\text {scat }}$} & $6.07-2.23 \mathrm{MeV}$ & 54.9 & 12.6 \\
\hline & & $19.6-6.07 \mathrm{MeV}$ & 84.6 & 15.6 \\
\hline
\end{tabular}

Table 12. Integral parameter uncertainties (\%) with initial and required cross section uncertainties.

\begin{tabular}{|l|l|l|l|l|l|l|}
\hline ABTR & SFR & EFR & GFR & LFR & VHTR & PWR \\
\hline
\end{tabular}

\begin{tabular}{|l|l|l|l|l|l|l|l|c|}
\hline \multirow{2}{*}{$\mathbf{k}_{\text {eff }}$ BOC } & initial & 0.62 & 1.04 & 0.79 & 1.24 & 0.88 & 0.37 & 0.36 \\
& final & 0.31 & 0.32 & 0.37 & 0.33 & 0.33 & 0.31 & 0.27 \\
\hline \multirow{2}{*}{$\mathbf{k}_{\text {eff }}$ EOC } & initial & - & - & - & - & - & 0.41 & 0.64 \\
\cline { 2 - 9 } & final & - & - & - & - & - & 0.31 & 0.37 \\
\hline \multirow{2}{*}{ Void } & initial & 5.11 & 15.66 & 6.68 & 5.46 & 4.97 & - & - \\
\cline { 2 - 9 } & final & 3.07 & 4.06 & 3.26 & 3.12 & 1.88 & - & - \\
\hline $\begin{array}{l}\text { Burn-up } \\
{[p c m]}\end{array}$ & initial & 37.4 & 152.1 & 584.9 & 254.2 & 127.7 & 487.0 & 684.6 \\
\cline { 2 - 9 } & final & 19.1 & 47.0 & 297.9 & 105.8 & 49.8 & 366.3 & 504.2 \\
\hline
\end{tabular}

differential and integral experiments in order to meet design target accuracies.

At first, a realistic assessment of the potential role of experimental techniques at existing experimental facilities, could help to streamline and prioritize new differential measurements. This effort should be as far as possible coordinated at an international level. In parallel, the use of integral experiments should be envisaged, to provide complementary information. In fact, a powerful strategy has been developed and recently generalized and applied to
Na-cooled fast reactors [3]. This strategy allows to reduce current uncertainties on design parameters, using integral experiments as much as possible "representative" of the corresponding integral parameters for the "reference" design.

In particular, in ref. [3] it is shown that in the case of ABTR, the use of appropriate integral experiments allows to reduce the uncertainty on the $\mathrm{k}_{\text {eff }}$ from $2.02 \%$ to $0.36 \%$. In the case of the SFR the reduction is significant but smaller (from $1.77 \%$ to $1.13 \%$ ), due to the fact that the chosen integral experiments are not sensitive enough to MA data.

\section{Summary and conclusions}

When reliable design target accuracies and nuclear data uncertainties are available, quantitative indications can be defined on priority needs for data uncertainty reductions. Requirements can obviously differ between fast and thermal neutron systems. The present status of nuclear data uncertainties, and in particular the very low values for U-235, $\mathrm{U}-238$ and $\mathrm{Pu}-239$ fission and capture uncertainties, allows to underline specific priority needs for fast systems. The present study indicates a priority requirement for a drastic uncertainty reduction for some $\sigma_{\text {inel }}$ (in particular for U-238), for the $\sigma_{\text {fiss }}$ of Pu-241 (between $\sim 1-500 \mathrm{keV}$ ) and of $\sigma_{\text {capt }}$ of Pu-239 ( 1$500 \mathrm{keV})$. These indications are valid for all the fast reactors considered in this work, and which are representative of the current priorities of the Gen-IV and GNEP initiatives. Other requirements are of course associated to specific systems (as $\mathrm{Si}$ data for the GFR or $\mathrm{Pb}$ in the case of LFR).

We have also investigated a method to tune the accuracy requirements on different cross-section types (e.g., inelastic and fission) according to the relative difficulty to achieve high accuracies in different types of measurement and more investigations in this field can be fruitful.

Since many of the requirements are very tight and difficult to be met within a reasonable time horizon, it seems that a strategy of combined use of integral and differential measurements should be pursued.

Finally, it should be stressed the essential role played by the recent effort in several laboratories to assess credible uncertainty data, which help to define a sound strategy for nuclear data improvements to meet the needs of future reactors and their associated fuel cycles.

\section{References}

1. M. Salvatores et al., Nuclear Data Needs for Advanced Reactor Systems. A NEA Nuclear Science Committee Initiative (these proceedings).

2. G. Aliberti et al., Nuclear data sensitivity, uncertainty and target accuracy assessment for future nuclear systems, Ann. Nucl. Energy 33, 700 (2006).

3. M. Salvatores, G. Aliberti, G. Palmiotti, Nuclear data validation and design performances uncertainty reduction, to be presented at ANS meeting (Boston, USA, June 2007). 